\title{
CES Plenary Session 1994. Points made in discussion of planning and priority setting
}

\author{
Tom Griffin \\ Statistical Division, ECE/UN, Palais des Nations, CH-1211 Geneva 10, Switzerland
}

1. "Strategic" of "Corporate" Planning, which has been practised in commercial companies for some time, is now also being introduced widely in non-profit institutions including governments and national statistical institutions.

2. A strategic plan, or similar tool, is necessary in order to provide direction or orientation.

3. Strategic planning may be more difficult in periods of uncertainty, as for many countries in transition, but may also be more important in such periods.

4. The most effective leaders have the full backing of their whole staff.

5. Everyone in an organization should be involved in the process.

6. In certain circumstances, the most junior staff may embrace the new strategic objectives of an organization more willingly than middle management.

7. Human resource development is fundamental.

8. The clients of the organisation must also be involved.

9. The strategic planning process must be very carefully managed.

10. The process of strategic planning is at least as important as the resulting strategic plans themselves. It is in any case a continuous one, and the drafting of the first strategic plan can be expected to take months or years.

11. The purpose of a strategic plan should not be to expound a doctrine but rather to agree upon a set of agreed strategic aims.

12. Natural cynicism is a barrier to the process of strategic planning and the devising of mission statements. Mission statements must be very brief and they inevitably appear obvious and commonplace though they may be important and focus the attention of an organization on its ultimate goal.

13. The Philips electronic giant which had been in some difficulty, spent two years devising a mission statement. The result could hardly have been more commonplace. It was: "We want our customers to be delighted at all times".

14. Priority setting although it should be approached scientifically, is nevertheless a matter of judgement at the end of the process. 
15. Strategic plans always read as "fine words" but they have no value if they are arrived at through the wrong process and if they do not finally guide decision making.

16. Nevertheless, "cosmetics" count. It is of benefit to the reputation of an institution to be able to show that it has thought carefully about its aim and that they are the aims that its customers would approve and appreciate.

17. Not only is it important that staff are involved in all stages of the process of strategic planning but it is also important that all staff are increasingly aware of user needs.

18. Staff understand users' needs better if statistical staff are users as well as producers of statistics.

19. Strategic planning is a mechanism for listening, both within the organization and outside.

20. There must be regular follow-up and feedback.

21. Mission statements and strategic plans do not work on their own. Neither does anything else. The whole culture of the organization should be appropriate to its functions.

22. Planning is very important but it does not exonerate senior managers from managing, and their main engagement function is the management of people. 